\title{
Impact of Age On Short-Term Outcomes After Discharge in Patients With Aneurysmal Subarachnoid Hemorrhage
}

\section{Masahiro Hosogai ( $\nabla$ d192530@hiroshima-u.ac.jp )}

Hiroshima University Graduate School of Biomedical and Health Sciences Health Sciences Major: Hiroshima Daigaku Igakubu Hoken Gakka https://orcid.org/0000-0001-7217-4446

Fusao Ikawa

Hiroshima University Graduate School of Biomedical and Health Sciences Health Sciences Major: Hiroshima Daigaku Igakubu Hoken Gakka Toshikazu Hidaka

Hiroshima University Graduate School of Biomedical and Health Sciences Health Sciences Major: Hiroshima Daigaku Igakubu Hoken Gakka

\section{Shingo Matsuda}

Hiroshima University Graduate School of Biomedical and Health Sciences Health Sciences Major: Hiroshima Daigaku Igakubu Hoken Gakka lori Ozono

Hiroshima University Graduate School of Biomedical and Health Sciences Health Sciences Major: Hiroshima Daigaku Igakubu Hoken Gakka

\section{Joji Inamasu}

Saiseikai Utsunomiya hospital, Utsunomiya

Hitoshi Kobata

Osaka Mishima Emergency Critical Care Center

Nobutaka Horie

Nagasaki University

Yuichi Murayama

The Jikei University School of Medicine

Akira Sato

Tokyo Kyosai Hospital

Yoko Kato

Fujita Health University Bantane Hospital

Hirotoshi Sano

Shinkawabashi Hospital

Shuhei Yamaguchi

Hospital Bureau of Shimane Prefecture

\section{Research Article}

Keywords: aneurysmal subarachnoid hemorrhage, elderly, modified World Federation of Neurosurgical Societies scale, outcomes after discharge

Posted Date: August 24th, 2021

DOl: https://doi.org/10.21203/rs.3.rs-787772/v1

License: (9) (7) This work is licensed under a Creative Commons Attribution 4.0 International License. Read Full License 


\section{Abstract}

Changes in outcome after discharge of patients with aneurysmal subarachnoid hemorrhage (aSAH) have not been examined in detail in recent aging society. This study aimed to clarify the prevalence and factors of changes in outcome in these patients based on a registry database in Japan. Overall, 1,111 radically treated patients with aSAH in the acute stage were selected between January 2010 and December 2012 for inclusion in the modified World Federation of Neurosurgical Societies (mWFNS) scale study. The modified Rankin Scale (mRS) score at discharge and 3 months after onset, prevalence of improvement and decline between these two periods, and their factors were evaluated by age groups through multivariate logistic regression analysis. The rates of improvement

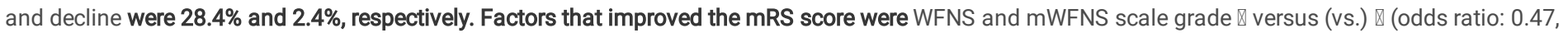
$95 \%$ confidence interval: $0.31-0.71)$, grade $\otimes$ vs. $\otimes(0.49,0.31-0.76)$, and cerebral vasospasm category 4 vs. $1(0.43,0.25-0.77)$. Factors that decreased the mRS score were pre-elderly (65-74 years) vs. non-elderly ( $<65$ years) $(5.65,1.09-29.20)$, elderly ( $\geq 75$ years) vs. non-elderly (19.20, $2.36-156.50)$, WFNS scale grade III vs. I, and aneurysmal location. Mild neurological grade on admission and no cerebral infarction due to cerebral vasospasm were the factors improving outcomes, and aging was a factor declining outcomes between discharge and at 3 months after onset. Careful assessment timing of outcome in elderly patients is needed in the future aging society.

\section{Introduction}

Aneurysmal subarachnoid hemorrhage (aSAH) is a severe type of hemorrhagic stroke with a mortality rate up to 35\%.[28] Approximately one-third of the survivors remain severely disabled and functionally dependent.[19] Although there are many reports examining the outcomes several months after onset of aSAH, $[3,4,6,8,10-12,15,20,21,29]$ few reports have discussed the changes in the prevalence of outcome at discharge and after discharge in recent aging situation.[2, 5, 18, 24, 25,30] There are only two reports, to date, of changes in the outcome of individual patients after discharge.[5, 30] According to these reports, approximately $60 \%$ of patients with aSAH had improved modified Rankin Scale (mRS) scores at 6 months after onset, and only one report mentioned a decrease in the mRS score after discharge.[30] Since the number of elderly patients with aSAH has been increasing recently, the number of cases in which the $\mathrm{mRS}$ score decreases after discharge may also increase. Therefore, to examine not only increases but also decreases in the mRS score after discharge would be desired in future aging population. In addition, short-term changes in post-discharge outcomes of elderly patients with aSAH should be examined.

Although the World Federation of Neurosurgical Societies (WFNS) scale has been used to classify the severity of aSAH, the modified WFNS (mWFNS) scale has been proposed to more accurately assess the clinical status of patients, in which patients with a Glasgow Coma Scale (GCS) score of 14 are assigned to grade II and those with a GCS score of 13 are assigned to grade III, regardless of the presence of neurologic deficits.[22] As a result, the mWFNS scale presumably enables more accurate prognostic assessment of patients with aSAH than the original scale. Because the changes in outcomes after discharge in relation to the WFNS and mWFNS scales have never been examined, we tried to investigate these relationships.

This study aimed to elucidate the prevalence and factors of changes in the outcome of patients with aSAH by age groups based on the registry database of the mWFNS scale study.

\section{Methods}

\section{Data sources}

Data for the present study were obtained from the 1,864 participants enrolled in the mWFNS scale study. This was a multicenter, prospective, observational study that included 38 neurosurgical institutions across Japan. Patients were enrolled from January 2010 to December 2012 . The mWFNS scale study prospectively collected the following relevant clinical data: age, sex, location of the ruptured aneurysm, each component of the GCS score, presence/type of associated neurologic deficits (weakness and/or aphasia), premorbid mRS score, medical complications, type of treatment used for aneurysm obliteration, type of perioperative complications, type of Fisher computed tomography (CT) group, and mRS scores at discharge and 3 months after onset. The details of data collection and management have been published elsewhere.[17, 22]

All patients were aged $\geq 15$ years, and the interval between onset and admission was $\leq 72$ hours in this cohort. Age was classified as follows: non-elderly $(\mathrm{NE}),<65$ years; pre-elderly (PE), 65-74 years; and elderly (E), $\geq 75$ years; according to the classification of the World Health Organization and the Japan Geriatrics Society.[16] The locations of the ruptured cerebral aneurysms were categorized as follows: anterior cerebral artery, anterior communicating artery, internal carotid artery-posterior communicating artery (ICPC), middle cerebral artery, other internal carotid artery (ICA), vertebral artery and basilar artery, and others. Other ICA was defined as any aneurysm that occurred in the ICA except for the ICPC. "Others" was defined as the aneurysm with an unclassified location. The cerebral vasospasm (VS) category due to aSAH was classified as follows: 1, none; 2 , slight and reversible decline without additional treatment; 3 , definitive but reversible decline with additional treatment; and 4, permanent deficit and/or appearance of a low-density area on CT.[23] In the current study, cerebral VS category 4 was defined as severe cerebral VS. Patients' outcomes were examined using the mRS score at discharge and 3 months after onset. Changes in the mRS score between discharge and at 3 months after onset were classified as follows: improvement, no change, and decline. Improvement was defined as a decrease in the mRS score, whereas decline was defined as an increase in the mRS score at 3 months after onset compared to that at admission. In the improvement group, patients with a mRS score of 0 at discharge were excluded. Multivariate logistic regression analysis was performed with the dichotomized improvement values of the mRS score from discharge versus (vs.) the follow-up at 3 months ( $1=$ improvement; $0=$ no improvement) as the dependent variable. The dichotomized decline values of the $\mathrm{mRS}$ score were $1=$ decline and $0=$ no decline.

\section{Study population}

We excluded 99 patients with a premorbid mRS score $\geq 3 ; 374$ whose mRS score was 6 at discharge; 81 who received treatment other than clipping or coiling; 65 who did not undergo radical treatment or underwent radical treatment $>72$ hours after onset; and 134 without the following information: age ( $=1$ ), WFNS 
scale grade or mWFNS scale grade at admission $(n=26)$, mRS score at discharge and 3 months after onset $(n=31)$, type of treatment $(n=18)$, location of the aneurysm $(n=21)$, pre-onset mRS score $(n=15)$, Fisher CT grade $(n=14)$, and cerebral VS category $(n=8)$. The remaining 1,111 patients were analyzed retrospectively (Fig. 1).

\section{Statistical analyses}

All statistical analyses were performed using JMP® Pro version 15 (SAS Institute, Cary, NC). Values are presented as the mean (standard deviation). Categorical variables were compared using the Fisher exact probability test. Continuous variables with normal distributions were analyzed using the Student ttest, and those with non-normal distributions were analyzed using the Mann-Whitney U-test. P-values $<0.05$ were considered statistically significant. The odds ratio (OR) and $95 \%$ confidence interval $(\mathrm{Cl})$ of $\mathrm{mRS}$ scores that changed between discharge and at 3 months after onset were evaluated through a multivariate logistic regression analysis. Variable selection in the multivariate analysis was determined according to clinical importance and existing literature, and no variable selection method, such as univariate or stepwise selection, was applied. Sex, age group, treatment type, location of the aneurysms, WFNS scale grade, mWFNS scale grade, and cerebral VS category were selected as variables.

\section{Review of the literature}

The literature search on the prevalence of changes in outcomes after discharge in patients with aSAH included articles published between January 2000 and January 2021. The search was performed on PubMed with publications restricted to those written in the English language, and the last search date was March 31,2021 . Keywords and free text searches used combinations of the following keywords: aneurysmal subarachnoid hemorrhage, change in outcome, and outcome at discharge. All reference sections of eligible studies and relevant reviews were reviewed further for potential studies. If a study generated multiple publications, the most current report was considered for the analysis.

\section{Results}

Patients' average (standard deviation) and median ages were 52.0 (9.3) and 54 years in the non-elderly group, 68.9 (2.8) and 68 years in the pre-elderly group, and 80.1 (3.9) and 80 years in the elderly group, respectively. Table 1 shows the baseline characteristics and outcomes in each group. While several factorsage, sex, location of the aneurysm, WFNS scale grade, mWFNS scale grade, cerebral VS category, mRS score at discharge, mRS score 3 months after onset, and change in the mRS score-were significantly different between the groups, the Fisher CT group was not. Of the 1,111 patients, 316 ( $28.4 \%)$ had improvement, 768 (69.1\%) had no change, and 27 (2.4\%) had decline in the mRS scores. 
Table 1

Baseline characteristics and outcomes of patients with ruptured cerebral aneurysm.

\begin{tabular}{|c|c|c|c|c|c|}
\hline Age group (y) & Total & Non-elderly, $<65$ & Preelderly, 65-74 & Elderly, $\geq 75$ & P-value \\
\hline No. & 1111 & 632 & 258 & 221 & \\
\hline Age, y, mean (SD) & $61.5(13.7)$ & $52.0(9.3)$ & $68.9(2.8)$ & $80.1(3.9)$ & $<0.001^{*}$ \\
\hline Age, y, median (IQR) & $62(52,72)$ & $54(46,60)$ & $68(67,71)$ & $80(77,83)$ & \\
\hline Sex (male, \%) & $371(33.4 \%)$ & $272(43.0 \%)$ & $63(24.4 \%)$ & $36(16.2 \%)$ & $<0.001^{*}$ \\
\hline Location of the aneurysms & & & & & $0.002^{*}$ \\
\hline ACA & $56(5.0 \%)$ & $34(5.4 \%)$ & $9(3.4 \%)$ & $13(5.9 \%)$ & \\
\hline AcoA & $281(25.3 \%)$ & $172(27.2 \%)$ & $63(24.4 \%)$ & $46(20.7 \%)$ & \\
\hline ICPC & $260(23.4 \%)$ & $120(19.0 \%)$ & $68(26.4 \%)$ & $72(32.9 \%)$ & \\
\hline MCA & $260(23.4 \%)$ & $148(23.5 \%)$ & $63(24.4 \%)$ & $49(22.1 \%)$ & \\
\hline Other ICA & $94(8.5 \%)$ & $67(10.6 \%)$ & $20(7.8 \%)$ & $7(3.2 \%)$ & \\
\hline VBA & $132(11.9 \%)$ & 78 (12.3\%) & $27(10.5 \%)$ & $27(12.2 \%)$ & \\
\hline Other & $28(2.5 \%)$ & $13(2.1 \%)$ & $8(3.1 \%)$ & $7(3.2 \%)$ & \\
\hline WFNS scale grade & & & & & $0.001^{*}$ \\
\hline I & $417(37.5 \%)$ & $268(42.4 \%)$ & $93(36.0 \%)$ & $56(25.2 \%)$ & \\
\hline II & $253(22.8 \%)$ & $144(22.8 \%)$ & $57(22.1 \%)$ & $52(23.4 \%)$ & \\
\hline III & $44(4.0 \%)$ & $20(3.2 \%)$ & $14(5.4 \%)$ & $10(4.5 \%)$ & \\
\hline IV & $232(20.9 \%)$ & $118(18.7 \%)$ & $53(20.5 \%)$ & $61(27.5 \%)$ & \\
\hline V & $166(14.9 \%)$ & $82(13.0 \%)$ & $42(16.3 \%)$ & $42(18.9 \%)$ & \\
\hline mWFNS scale grade & & & & & $0.003^{*}$ \\
\hline I & 417 (37.5\%) & $268(42.3 \%)$ & $93(36.0 \%)$ & $56(25.2 \%)$ & \\
\hline II & $203(18.3 \%)$ & $112(17.7 \%)$ & 49 (19.0\%) & $42(18.9 \%)$ & \\
\hline III & $94(8.5 \%)$ & $52(8.2 \%)$ & $22(8.5 \%)$ & $20(9.0 \%)$ & \\
\hline IV & 232 (20.9\%) & $118(18.8 \%)$ & $53(20.5 \%)$ & $61(27.5 \%)$ & \\
\hline V & $165(14.9 \%)$ & $82(13.0 \%)$ & 41 (15.9\%) & $42(18.9 \%)$ & \\
\hline Fisher CT group & & & & & 0.076 \\
\hline 1 & $57(5.1 \%)$ & $33(5.2 \%)$ & $15(5.8 \%)$ & $9(4.1 \%)$ & \\
\hline 2 & 150 (13.5\%) & $89(14.1 \%)$ & $43(16.7 \%)$ & $18(8.1 \%)$ & \\
\hline 3 & $902(81.2 \%)$ & $508(80.4 \%)$ & $198(76.7 \%)$ & 194 (87.4\%) & \\
\hline 4 & $4(0.4 \%)$ & $2(0.3 \%)$ & $2(0.8 \%)$ & $0(0.0 \%)$ & \\
\hline Cerebral VS category & & & & & $0.039^{*}$ \\
\hline 1 & $842(75.8 \%)$ & 477 (75.5\%) & $200(77.5 \%)$ & 165 (74.7\%) & \\
\hline 2 & 103 (9.3\%) & $62(9.6 \%)$ & $23(8.9 \%)$ & $18(8.1 \%)$ & \\
\hline 3 & 85 (7.7\%) & 58 (9.2\%) & $15(5.8 \%)$ & $12(5.4 \%)$ & \\
\hline 4 & $82(7.4 \%)$ & $36(5.7 \%)$ & $20(7.8 \%)$ & $26(11.7 \%)$ & \\
\hline mRS score at discharge & & & & & $<0.001^{*}$ \\
\hline 0 & 371 (33.4\%) & $266(42.2 \%)$ & $79(30.6 \%)$ & $26(11.7 \%)$ & \\
\hline 1 & 199 (17.9\%) & 124 (19.6\%) & $44(17.1 \%)$ & 31 (14.0\%) & \\
\hline 2 & $143(12.9 \%)$ & 79 (12.3\%) & $30(11.6 \%)$ & $34(15.3 \%)$ & \\
\hline 3 & 101 (9.1\%) & $51(8.1 \%)$ & $25(9.7 \%)$ & $25(11.3 \%)$ & \\
\hline 4 & $175(15.8 \%)$ & 73 (11.5\%) & 49 (19.0\%) & $53(23.9 \%)$ & \\
\hline
\end{tabular}






The results of multivariate logistic regression analysis of the group with improved mRS scores between discharge and at 3 months after onset are presented in Table 2 and Fig. 2. In the improvement group, patients with an mRS score of 0 at discharge $(n=371)$ were excluded. Of the remaining 740 patients, 316 $(42.7 \%)$ had improved mRS scores. The significant factors for improvement of mRS scores between discharge and at 3 months after onset were the WFNS

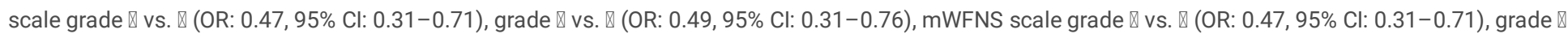
vs. $\otimes$ (OR: $0.49,95 \% \mathrm{Cl}$ : $0.31-0.76$ ), and cerebral VS category 4 vs. 1 (OR: $0.43,95 \% \mathrm{Cl}: 0.25-0.77$ ). Multivariate logistic regression analysis data for the group with declined mRS scores between discharge and at 3 months after onset are presented in Table 3 and Fig. 3. Of the 1,111 patients, 27 (2.4\%) had decreased mRS scores. The significant factors for decline of the mRS score between discharge and at 3 months after onset were PE vs. NE (OR: 5.65, 95\% Cl: 1.0929.20), E vs. NE (OR: 19.20, 95\% Cl: 2.36-156.50), WFNS scale grade III vs. I (OR: 5.86, 95\% Cl: 1.64-20.87), and other ICA vs. ICPC (OR 4.48: 95\% Cl 1.0820.15). 
Table 2

Results of multivariate logistic regression analysis of the group with improvement based on the mRS score between discharge and at 3 months after onset

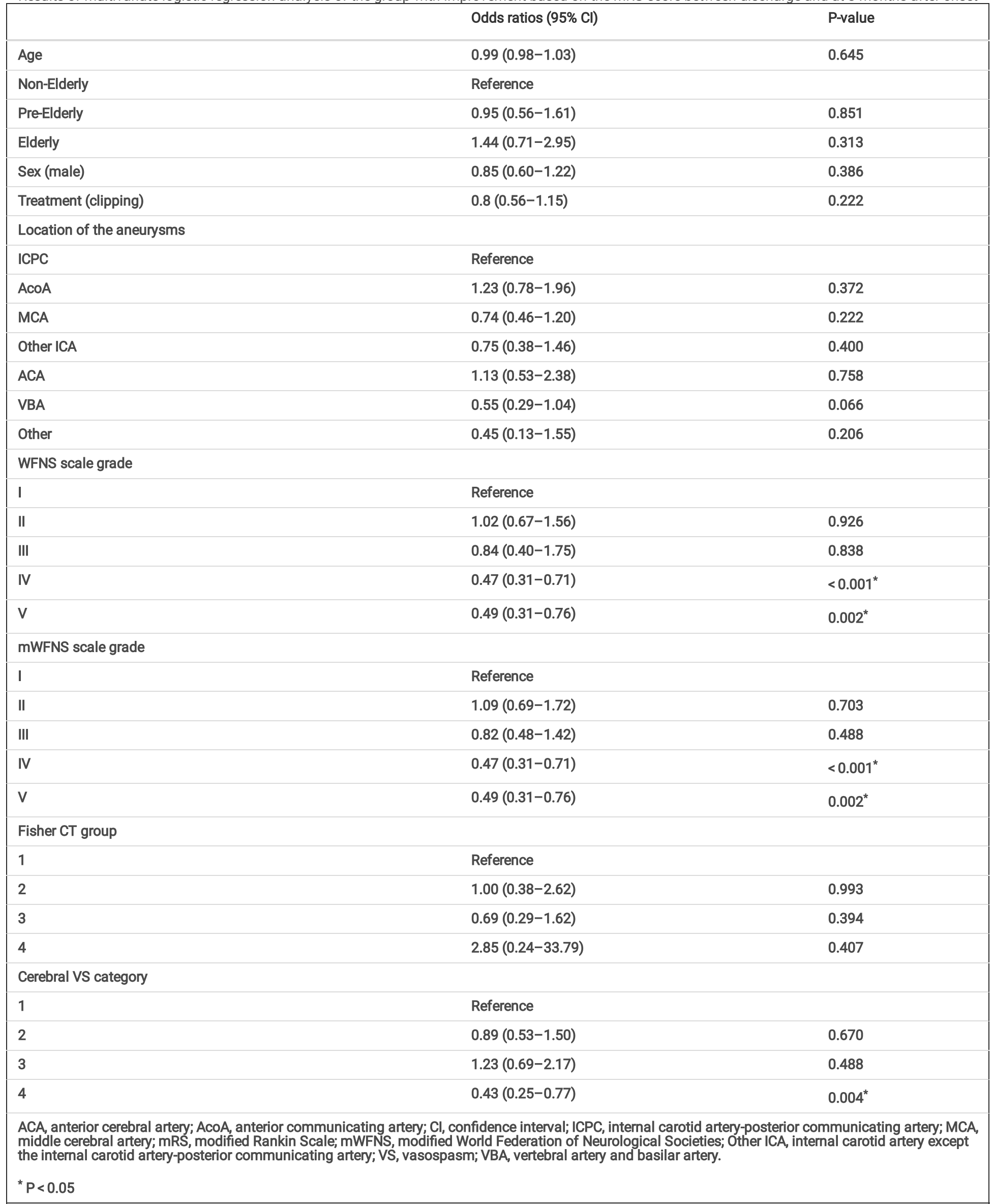


Table 3

Results of multivariate logistic regression analysis of the group with decline based on the mRS score between discharge and at 3 months after onset

\begin{tabular}{|c|c|c|}
\hline & Odds ratios $(95 \% \mathrm{Cl})$ & $P$ value \\
\hline Age & $0.94(0.89-1.01)$ & 0.051 \\
\hline Non-Elderly & Reference & \\
\hline Pre-Elderly & $5.65(1.09-29.20)$ & $0.039^{*}$ \\
\hline Elderly & $19.20(2.36-156.50)$ & $0.006^{*}$ \\
\hline Sex (male) & $0.77(0.28-2.09)$ & 0.605 \\
\hline Treatment (clipping) & $0.49(0.20-1.20)$ & 0.118 \\
\hline \multicolumn{3}{|c|}{ Location of the aneurysms } \\
\hline ICPC & Reference & \\
\hline AcoA & $0.95(0.23-3.88)$ & 0.940 \\
\hline MCA & $1.60(0.43-6.03)$ & 0.484 \\
\hline Other ICA & $4.48(1.08-20.15)$ & $0.039^{*}$ \\
\hline $\mathrm{ACA}$ & $2.35(0.39-14.01)$ & 0.350 \\
\hline VBA & $0.80(0.15-4.37)$ & 0.801 \\
\hline Other & $1.23(0.07-20.89)$ & 0.889 \\
\hline \multicolumn{3}{|l|}{ WFNS scale grade } \\
\hline I & Reference & \\
\hline ॥ & $0.47(0.10-2.26)$ & 0.344 \\
\hline III & $5.86(1.64-20.87)$ & $0.006^{*}$ \\
\hline IV & $2.08(0.75-5.82)$ & 0.162 \\
\hline v & $2.21(0.73-6.68)$ & 0.160 \\
\hline \multicolumn{3}{|l|}{ mWFNS scale grade } \\
\hline I & Reference & \\
\hline II & $0.58(0.12-2.83)$ & 0.503 \\
\hline III & $2.60(0.75-9.08)$ & 0.133 \\
\hline IV & $2.08(0.75-5.82)$ & 0.162 \\
\hline V & $2.21(0.73-6.68)$ & 0.160 \\
\hline \multicolumn{3}{|l|}{ Fisher CT group } \\
\hline 1 & Reference & \\
\hline 2 & N/A (N/A) & 0.998 \\
\hline 3 & N/A (N/A) & 0.998 \\
\hline 4 & $1.06(0.28-4.21)$ & 0.901 \\
\hline \multicolumn{3}{|l|}{ Cerebral VS category } \\
\hline 1 & Reference & \\
\hline 2 & $0.64(0.13-3.10)$ & 0.577 \\
\hline 3 & $0.91(0.19-4.37)$ & 0.905 \\
\hline 4 & $1.72(0.49-6.05)$ & 0.401 \\
\hline \multicolumn{3}{|c|}{$\begin{array}{l}\text { ACA, anterior cerebral artery; AcoA, anterior communicating artery; Cl, confidence interval; ICPC, internal carotid artery-posterior communicating artery; MCA, } \\
\text { middle cerebral artery; mRS, modified Rankin Scale; mWFNS, modified World Federation of Neurological Societies; Other ICA, internal carotid artery except } \\
\text { the internal carotid artery-posterior communicating artery; VS, vasospasm; VBA, vertebral artery and basilar artery. } \\
{ }^{*} \mathrm{P}<0.05\end{array}$} \\
\hline
\end{tabular}

Literature review 
Among the 98 papers, we selected satisfactory six papers for review. The prevalence of changes in outcome after discharge in patients with aSAH is presented in Table 4. The changes in the prevalence of good outcome (mRS score: 0-2 or Glasgow Outcome Score: 4-5) between discharge and the last follow-up ranged from $8.4-55.2 \% .[2,5,18,24,25,30]$ The prevalence of improvement of mRS scores in total cases between discharge and at 6 months ranged from $57.4-61.0 \%,[5,30]$ and the prevalence of declined $\mathrm{mRS}$ scores during the same period was $17.0 \%$.[30]

Table 4

Prevalence and changes of good outcome after discharge according to the literature review

\begin{tabular}{|c|c|c|c|c|c|c|c|c|c|c|c|c|c|}
\hline \multirow[t]{2}{*}{ No. } & \multirow[t]{2}{*}{ Reference } & \multirow[t]{2}{*}{ Year } & \multirow[t]{2}{*}{ Country } & \multirow{2}{*}{$\begin{array}{l}\text { Number } \\
\text { of } \\
\text { patients } \\
\text { with } \\
\text { aSAH }\end{array}$} & \multirow{2}{*}{$\begin{array}{l}\text { Age (y) } \\
\text { Median }\end{array}$} & \multicolumn{5}{|c|}{$\begin{array}{l}\text { Prevalence of good outcome, mRS score 0-2 } \\
(\%)\end{array}$} & \multirow{2}{*}{$\begin{array}{l}\text { Changes } \\
\text { in the } \\
\text { prevalence } \\
\text { of good } \\
\text { outcome } \\
(\%)\end{array}$} & \multicolumn{2}{|c|}{$\begin{array}{l}\text { Prevalence of change in } \\
\text { total cases }(\%)\end{array}$} \\
\hline & & & & & & Discharge & $\begin{array}{l}3 \\
\text { months }\end{array}$ & $\begin{array}{l}6 \\
\text { months }\end{array}$ & $\begin{array}{l}1 \\
\text { year }\end{array}$ & $\begin{array}{l}>1 \\
\text { year }\end{array}$ & & Improvement & Decline \\
\hline 1 & $\begin{array}{l}\text { Wilson et } \\
\text { al. }{ }^{14}\end{array}$ & 2013 & U.S. & 88 & $56.6^{\dagger}$ & 11.3 & - & 42.7 & - & - & 31.4 & 61.0 & 17.0 \\
\hline 2 & $\begin{array}{l}\text { Platz et } \\
\text { al. }^{18}\end{array}$ & 2013 & Germany & 741 & 53 & $37.9 \neq$ & & $58.0^{\ddagger}$ & - & - & $20.1^{\ddagger}$ & - & - \\
\hline 3 & $\begin{array}{l}\text { Schwartz } \\
\text { et al. }{ }^{15 \star}\end{array}$ & 2017 & Germany & 107 & 53 & 0.0 & - & - & - & 55.2 & 55.2 & - & - \\
\hline 4 & $\begin{array}{l}\text { Ariyada } \\
\text { et al. }{ }^{16 *}\end{array}$ & 2020 & Japan & 145 & 64 & 0.0 & - & - & 16 & - & 16 & - & - \\
\hline 5 & $\begin{array}{l}\text { Hammer } \\
\text { et al. }{ }^{19}\end{array}$ & 2020 & Germany & 203 & 55.1 & 44.3 & - & 52.7 & - & - & 8.4 & 57.4 & - \\
\hline 6 & $\begin{array}{l}\text { Schatlo } \\
\text { et al. }{ }^{17}\end{array}$ & 2021 & Switzerland & 1787 & 56 & 49.9 & - & - & 64.4 & - & 14.5 & - & - \\
\hline 7 & $\begin{array}{l}\text { Present } \\
\text { study }\end{array}$ & 2021 & Japan & 1111 & 62 & 64.2 & 71.1 & - & - & - & 6.9 & 28.4 & 2.4 \\
\hline
\end{tabular}

aSAH, aneurysmal subarachnoid hemorrhage; mRS, modified Rankin Scale; no., number, WFNS, modified World Federation of Neurological Societies; U.S., United States.

${ }^{*}$, WFNS scale grade IV or V on admission; ${ }^{\dagger}$, mean; ${ }^{\ddagger}$, Glasgow Outcome Score 4-5

\section{Discussion}

\section{Prevalence of changes in outcomes after discharge}

In the current study of 1,111 patients, the prevalence of improvement, no change, and decline was $28.4 \%, 69.1 \%$, and $2.4 \%$, respectively, of mRS scores between discharge and at 3 months after onset in Table 1. As described in Table 4, Hammer et al. reported that 116 of 202 patients (57.4\%) had an improved mRS score between discharge and at 6 months.[5] According to Wilson et al.'s study, 88 cases of poor-grade aSAH were analyzed, and $61.0 \%$ of patients had an improved $\mathrm{mRS}$ score between discharge and at 6 months.[30] Compared to these reports, our study shows lower prevalence (28.4\%) of improved mRS scores. According to past reports, the average length of hospital stay for patients with aSAH in Japan was approximately twice longer (32-37 days) than that in the United States (16.9-18.4 days). [1, 9]This accounts for the fact that Japan has a universal health insurance system and provides treatment for cerebral vasospasm and ventriculoperitoneal shunting for hydrocephalus during hospitalization.[7] In addition, our study evaluated the mRS score at 3 months after discharge, which was a shorter term than those reported in previous studies.

In the present study, as shown in Table 3, only $2.4 \%$ of patients had deteriorated mRS scores after discharge. As described in Table 4, Wilson et al. reported that $17.0 \%$ of patients had deteriorated mRS scores between discharge and at 6 months after onset.[30] Same reasons of longer hospital stay in Japan and short-term outcome can account for this lower rate of decline. Since results of these studies show that the prevalence of improvement in outcome at several months after discharge is higher than that of decline in outcome, the outcomes after aSAH are likely to improve in the several months after discharge.

\section{The factors for improvement of mRS scores after discharge}

In this study, WFNS and mWFNS scale grades IV and V were inverse risks compared with grade I, for the improvement of mRS scores between discharge and at 3 months after onset. Namely, mild neurological grade on admission was the factors improving outcomes. Hammer et al. reported that WFNS grade I or II were significant factors of improvement from discharge to 6 months after onset (WFNS I-II vs. III-V: OR 4.77; 95\% Cl 1.51-15.05; $p=0.0077$ ) in the multivariate analysis,[5] which supports our results.

In our study, cerebral VS category 4 was also an inverse risk compared with category 1 for the improvement of mRS scores between discharge and at 3 months after onset. The absence of a stroke played an important role in the prediction of early outcome improvement in the univariate analysis in another study.[5] Therefore, it is considered that the absence of cerebral infarction due to cerebral vasospasm after sSAH is involved in improving the outcome after discharge. 


\section{The factors for decline of the mRS score after discharge}

Although, there are no reports on the factors for decline of the mRS score after discharge in the past, several factors for declining mRS scores were confirmed in this study.

The risk factors regarding the age for the decline of $\mathrm{mRS}$ were $\mathrm{PE}$ and $\mathrm{E}$ in the multivariate analysis. This fact means that aging is a factor for declining outcomes even in the short-term after discharge. In patients with aSAH, older age may worsen the short-term outcome after discharge; therefore, the assessment timing of outcome for aSAH should be carefully determined in the future aging society.

Regarding the aneurysm location, cases of other ICA location had significantly decreased mRS scores between discharge and at 3 months after onset compared to cases of ICPC in the current study. Why other ICA locations caused patients' outcomes to significantly decline after discharge compared to the ICPC location may be due to the small number of samples in the decline group.

\section{Regarding the mWFNS scale grade}

WFNS scale grade III vs. I was the significant factor for decreased mRS scores after discharge. WFNS scale grade III is a special entity with focal neurological deficit (GCS score of 13 or 14 ) that included only $4.0 \%$ of our cohort. Previous reports have shown that the proportion of WFNS scale grade III is only $2 \%-9 \%$, $[13,14,26,27,31]$ which is as infrequent as ours. Given the low proportion of WFNS scale grade III, WFNS scale grade III may be underestimated. On the other hand, the proportion of mWFNS scale grade III is $8.5 \%$ as shown in Table 1, which is higher than that of the WFNS scale. As previously reported, the mWFNS scale presumably may enable more accurate prognostic assessment of patients with aSAH compared to the original WFNS scale.[22]

\section{Prevalence and changes in good outcome after discharge according to the literature review}

As shown in Table 4, changes in the prevalence of good outcome after discharge were $8.4-55.2 \%$ according to the literature review. $[2,5,18,24,25,30]$ In contrast, that of our study was lower at $6.9 \%$. The reasons for this are thought to be due to the shorter evaluation period after discharge and the higher proportion of good outcomes at discharge in our study compared to those in the previous reports.

\section{Limitations}

The present study has several limitations. First, this was not a randomized controlled study, and the initial purpose of the mWFNS scale study was to evaluate the ability of the mWFNS scale to predict outcomes. These data were derived from a post-hoc analysis, and the original study was not designed to account for various factors. Second, because of the lack of independent physicians, the GCS and mRS scores were evaluated by neurosurgeons in each institute who were not blinded to the treatment and these ratings were not standardized; therefore, these values may be potentially biased. Third, in this database, the follow-up period was limited to 3 months after onset. We could not assess long-term statuses of the patients. If possible, a longer observation study may be necessary in the future. Fourth, the current results may not be generalized to other countries with different medical resources and systems. Therefore, the results of this study should be interpreted with caution. These data included only a limited set of aSAH cases in Japan, which has the largest elderly population in the world. Fifth, in the present study, the efficacy of the mWFNS scale in assessing the prognosis of the patients with aSAH was not compared to that of the original WFNS scale. To determine the efficacy of the mWFNS scale for outcome evaluation in patients with aSAH, more precise evaluation between GCS scores 13 and 14 would be necessary based on various factors and should be refined in the future. Further randomized controlled trials with diverse participants are also warranted.

\section{Conclusions}

Mild neurological grade on admission and absence of cerebral infarction due to cerebral VS category were the factors improving outcomes, and aging was a factor declining outcomes between discharge and at 3 months after onset. Careful assessment timing of outcome is necessary for aSAH in the future aging society.

\section{Abbreviations}

aSAH, aneurysmal subarachnoid hemorrhage; Cl, confidence interval; CT, computed tomography; E, elderly; GCS, Glasgow Coma Scale; ICA, internal carotid artery; ICPC, internal carotid artery-posterior communicating artery; mRS, modified Rankin Scale; mWFNS, modified World Federation of Neurosurgical Societies; NE, non-elderly; OR, odds ratio; PE, pre-elderly; VS, vasospasm; vs., versus; WFNS, World Federation of Neurosurgical Societies

\section{Declarations}

Funding information This study was funded by the Pfizer Health Research Foundation Japan 2019 (19-E-01) and the Japan Society for the Promotion of Science Grant-in-Aid for Scientific Research (C) 17K10829. The funders of the study had no role in the study design, data collection, data analysis, data interpretation, or writing of the report.

Date availability Not applicable.

Compliance with ethical standards

Conflict of interest The authors report no conflict of interest concerning the materials or methods used in this study or the findings specified in this paper. 
Authors' contribution All authors have made substantial contributions to the intellectual content of the paper, contributed to data interpretation, approved the final manuscript, and agree with submission to this journal.

Ethics approval This study was approved by the institutional review boards of each institution (Numbers: E-328 and 11-005) using anonymous data.

Informed consent The requirement for informed consent was waived because of the anonymous nature of the data and the opt out method.

Code availability Not applicable.

\section{References}

1. Adamczak S, Fritz R, Patel D, Geh N, Laurent D, Polifka A, Hoh BL, Fox WC (2020) Trends in hospital-to-hospital transfers for aneurysmal subarachnoid hemorrhage: a single-institution experience from 2006 to 2017. World Neurosurg. https://doi.org/10.1016/j.wneu.2020.11.111

2. Ariyada K, Ohida T, Shibahashi K, Hoda H, Hanakawa K, Murao M (2020) Long-term Functional Outcomes for World Federation of Neurosurgical Societies Grade V Aneurysmal Subarachnoid Hemorrhage after Active Treatment. Neurol Med Chir (Tokyo) 60:390-396. https://doi.org/10.2176/nmc.oa.20200052

3. Chiang VL, Claus EB, Awad IA (2000) Toward more rational prediction of outcome in patients with high-grade subarachnoid hemorrhage. Neurosurgery 46:28-35; discussion $35-26$

4. Duke BJ, Kindt GW, Breeze RE (1998) Outcome after urgent surgery for grade IV subarachnoid hemorrhage. Surg Neurol 50:169-173. https://doi.org/10.1016/s0090-3019(97)00449-7

5. Hammer A, Ranaie G, Yakubov E, Erbguth F, Holtmannspoetter M, Steiner HH, Janssen H (2020) Dynamics of outcome after aneurysmal subarachnoid hemorrhage. Aging 12:7207-7217. https://doi.org/10.18632/aging.103069

6. Hutchinson PJ, Power DM, Tripathi P, Kirkpatrick PJ (2000) Outcome from poor grade aneurysmal subarachnoid haemorrhage-which poor grade subarachnoid haemorrhage patients benefit from aneurysm clipping? Br J Neurosurg 14:105-109. https://doi.org/10.1080/02688690050004516

7. Ikawa F, Hidaka T, Yoshiyama M, Ohba H, Matsuda S, Ozono I, lihara K, Kinouchi H, Nozaki K, Kato Y, Morita A, Michihata N, Yasunaga H, Kurisu K (2019) Characteristics of cerebral aneurysms in Japan. Neurol Med Chir (Tokyo) 59:399-406. https://doi.org/10.2176/nmc.ra.2019-0099

8. Jr Kassell HE, Torner N J (1992) The International Cooperative Study on the Timing of Aneurysm Surgery. The North American experience. Stroke 23:205214. https://doi.org/10.1161/01.str.23.2.205

9. Kurogi R, Kada A, Nishimura K, Kamitani S, Nishimura A, Sayama T, Nakagawara J, Toyoda K, Ogasawara K, Ono J, Shiokawa Y, Aruga T, Miyachi S, Nagata I, Matsuda S, Yoshimura S, Okuchi K, Suzuki A, Nakamura F, Onozuka D, Hagihara A, lihara K (2018) Effect of treatment modality on in-hospital outcome in patients with subarachnoid hemorrhage: a nationwide study in Japan (J-ASPECT Study). J Neurosurg 128:1318-1326. https://doi.org/10.3171/2016.12.jns161039

10. Laidlaw JD, Siu KH (2003) Poor-grade aneurysmal subarachnoid hemorrhage: outcome after treatment with urgent surgery. Neurosurgery 53:1275-1282. https://doi.org/10.1227/01.neu.0000093199.74960.ff

11. Lanzino G, Kassell NF, Germanson TP, Kongable GL, Truskowski LL, Torner JC, Jane JA (1996) Age and outcome after aneurysmal subarachnoid hemorrhage: why do older patients fare worse? J Neurosurg 85:410-418. https://doi.org/10.3171/jns.1996.85.3.0410

12. Le Roux PD, Elliott JP, Newell DW, Grady MS, Winn HR (1996) Predicting outcome in poor-grade patients with subarachnoid hemorrhage: a retrospective review of 159 aggressively managed cases. J Neurosurg 85:39-49. https://doi.org/10.3171/jns.1996.85.1.0039

13. Macdonald RL, Kassell NF, Mayer S, Ruefenacht D, Schmiedek P, Weidauer S, Frey A, Roux S, Pasqualin A (2008) Clazosentan to overcome neurological ischemia and infarction occurring after subarachnoid hemorrhage (CONSCIOUS-1): randomized, double-blind, placebo-controlled phase 2 dose-finding trial. Stroke 39:3015-3021. https://doi.org/10.1161/strokeaha.108.519942

14. Molyneux A, Kerr R, Stratton I, Sandercock P, Clarke M, Shrimpton J, Holman R (2002) International Subarachnoid Aneurysm Trial (ISAT) of neurosurgical clipping versus endovascular coiling in 2143 patients with ruptured intracranial aneurysms: a randomised trial. Lancet 360:1267-1274. https://doi.org/10.1016/s0140-6736(02)11314-6

15. O'Sullivan MG, Sellar R, Statham PF, Whittle IR (1996) Management of poor grade patients after subarachnoid haemorrhage: the importance of neuroradiological findings on clinical outcome. Br J Neurosurg 10:445-452. https://doi.org/10.1080/02688699647069

16. Orimo H, Ito H, Suzuki T, Araki A, Hosoi T, Sawabe M (2006) Reviewing the definition of "elderly". Geriatr Gerontol Int 6:149-158. https://doi.org/10.1111/j.1447-0594.2006.00341.x

17. Ozono I, Ikawa F, Hidaka T, Yoshiyama M, Matsuda S, Michihata N, Kobata H, Murayama Y, Sato A, Kato Y, Sano H, Yamaguchi S, Kurisu K (2020) Risk factor for poor outcome in elderly patients with aneurysmal subarachnoid hemorrhage based on post hoc analysis of the modified WFNS scale study. World Neurosurg 141:e466-e473. https://doi.org/10.1016/j.wneu.2020.05.196

18. Platz J, Güresir E, Schuss P, Konczalla J, Seifert V, Vatter H (2013) The Impact of the Body Mass Index on Outcome After Subarachnoid Hemorrhage. Neurosurgery 73:201-208. https://doi.org/10.1227/01.neu.0000430322.17000.82

19. Rinkel GJ, Algra A (2011) Long-term outcomes of patients with aneurysmal subarachnoid haemorrhage. Lancet Neurol 10:349-356. https://doi.org/10.1016/s1474-4422(11)70017-5

20. Roquer J, Cuadrado-Godia E, Guimaraens L, Conesa G, Rodríguez-Campello A, Capellades J, García-Arnillas MP, Fernández-Candil JL, Avellaneda-Gómez C, Giralt-Steinhauer E, Jiménez-Conde J, Soriano-Tárraga C, Villalba-Martínez G, Vivanco-Hidalgo RM, Vivas E, Ois A (2020) Short- and long-term outcome of patients with aneurysmal subarachnoid hemorrhage. Neurology 95:e1819-e1829. https://doi.org/10.1212/wnl.0000000000010618 
21. Rosen DS, Macdonald RL (2004) Grading of Subarachnoid Hemorrhage: Modification of the World Federation of Neurosurgical Societies Scale on the Basis of Data for a Large Series of Patients. Neurosurgery 54:566-576. https://doi.org/10.1227/01.Neu.0000108862.32404.A5

22. Sano H, Satoh A, Murayama Y, Kato Y, Origasa H, Inamasu J, Nouri M, Cherian I, Saito N, members of the 38 registered i, Disease WC, Treatment C (2015) Modified World Federation of Neurosurgical Societies subarachnoid hemorrhage grading system. World Neurosurg 83:801-807.

https://doi.org/10.1016/j.wneu.2014.12.032

23. Satoh A, Sugiyama T, Ooigawa H, Nakajima H, Ogura T, Neki H, Morikawa E (2010) Prevention of symptomatic vasospasm by continuous cisternal irrigation with mock-CSF containing ascorbic acid and Mg(2+). Acta Neurochir Suppl 107:115-118. https://doi.org/10.1007/978-3-211-99373-6_19

24. Schatlo B, Fung C, Stienen MN, Fathi AR, Fandino J, Smoll NR, Zumofen D, Daniel RT, Burkhardt J-K, Bervini D, Marbacher S, Reinert M, D’Alonzo D, Ahlborn P, Mendes Pereira V, Roethlisberger M, Seule M, Kerkeni H, Remonda L, Weyerbrock A, Woernle K, Venier A, Perren F, Sailer M, Robert T, Rohde V, Schöni D, Goldberg J, Nevzati E, Diepers M, Gralla J, Z'Graggen W, Starnoni D, Woernle C, Maldaner N, Kulcsar Z, Mostaguir K, Maduri R, Eisenring C, Bernays R, Ferrari A, Dan-Ura H, Finkenstädt S, Gasche Y, Sarrafzadeh A, Jakob SM, Corniola M, Baumann F, Regli L, Levivier M, Hildebrandt G, Landolt H, Mariani L, Guzman R, Beck J, Raabe A, Keller E, Bijlenga P, Schaller K (2021) Incidence and outcome of aneurysmal subarachnoid hemorrhage:the Swiss Study on Subarachnoid Hemorrhage (Swiss SOS). Stroke 52:344-347. https://doi.org/10.1161/strokeaha.120.029538

25. Schwartz C, Pfefferkorn T, Ebrahimi C, Ottomeyer C, Fesl G, Bender A, Straube A, Pfister H-W, Heck S, Tonn J-C, Schichor C (2017) Long-term Neurological Outcome and Quality of Life after World Federation of Neurosurgical Societies Grades IV and V Aneurysmal Subarachnoid Hemorrhage in an Interdisciplinary Treatment Concept. Neurosurgery 80:967-974. https://doi.org/10.1093/neuros/nyw138

26. Todd MM, Hindman BJ, Clarke WR, Torner JC (2005) Mild intraoperative hypothermia during surgery for intracranial aneurysm. N Engl J Med 352:135145. https://doi.org/10.1056/NEJMoa040975

27. van den Bergh WM, Algra A, van Kooten F, Dirven CM, van Gijn J, Vermeulen M, Rinkel GJ (2005) Magnesium sulfate in aneurysmal subarachnoid hemorrhage: a randomized controlled trial. Stroke 36:1011-1015. https://doi.org/10.1161/01.Str.0000160801.96998.57

28. van Donkelaar CE, Bakker NA, Birks J, Veeger N, Metzemaekers JDM, Molyneux AJ, Groen RJM, van Dijk JMC (2019) Prediction of Outcome After Aneurysmal Subarachnoid Hemorrhage. Stroke 50:837-844. https://doi.org/10.1161/strokeaha.118.023902

29. van Donkelaar CE, Bakker NA, Veeger NJ, Uyttenboogaart M, Metzemaekers JD, Eshghi O, Mazuri A, Foumani M, Luijckx GJ, Groen RJ, van Dijk JM (2017) Prediction of outcome after subarachnoid hemorrhage: timing of clinical assessment. J Neurosurg 126:52-59.

https://doi.org/10.3171/2016.1.Jns152136

30. Wilson DA, Nakaji P, Albuquerque FC, McDougall CG, Zabramski JM, Spetzler RF (2013) Time course of recovery following poor-grade SAH: the incidence of delayed improvement and implications for SAH outcome study design. J Neurosurg 119:606-612. https://doi.org/10.3171/2013.4.jns121287

31. Wong GK, Poon WS, Chan MT, Boet R, Gin T, Ng SC, Zee BC (2010) Intravenous magnesium sulphate for aneurysmal subarachnoid hemorrhage (IMASH): a randomized, double-blinded, placebo-controlled, multicenter phase III trial. Stroke 41:921-926. https://doi.org/10.1161/strokeaha.109.571125

\section{Figures}




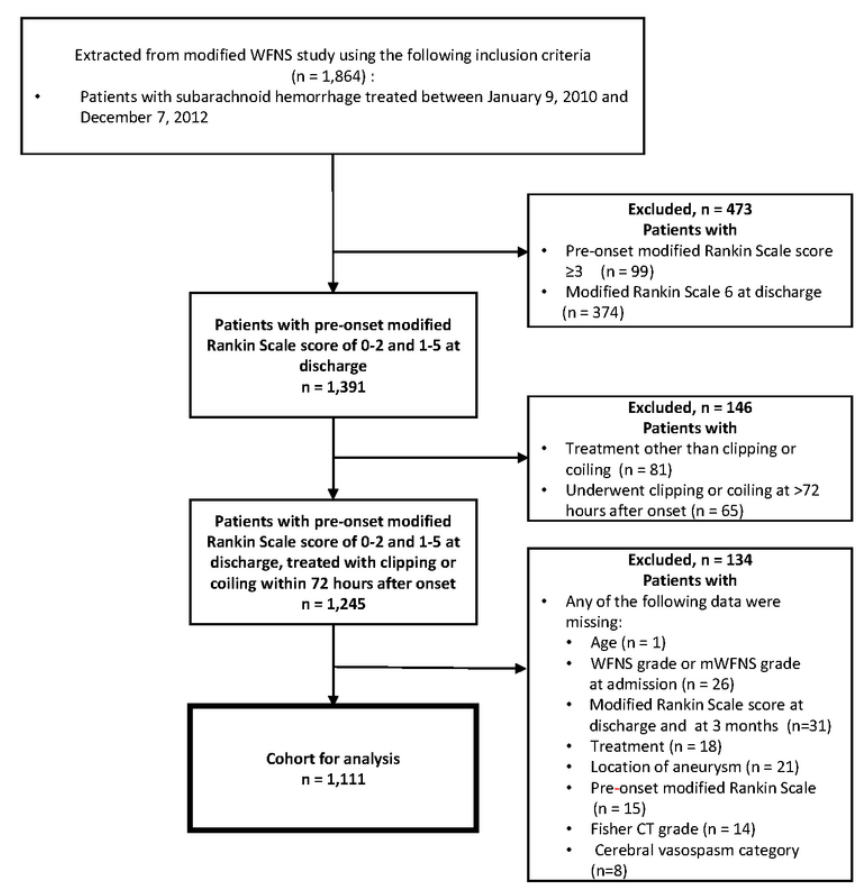

\section{Figure 1}

Selection of patients with aneurysmal subarachnoid hemorrhage. 


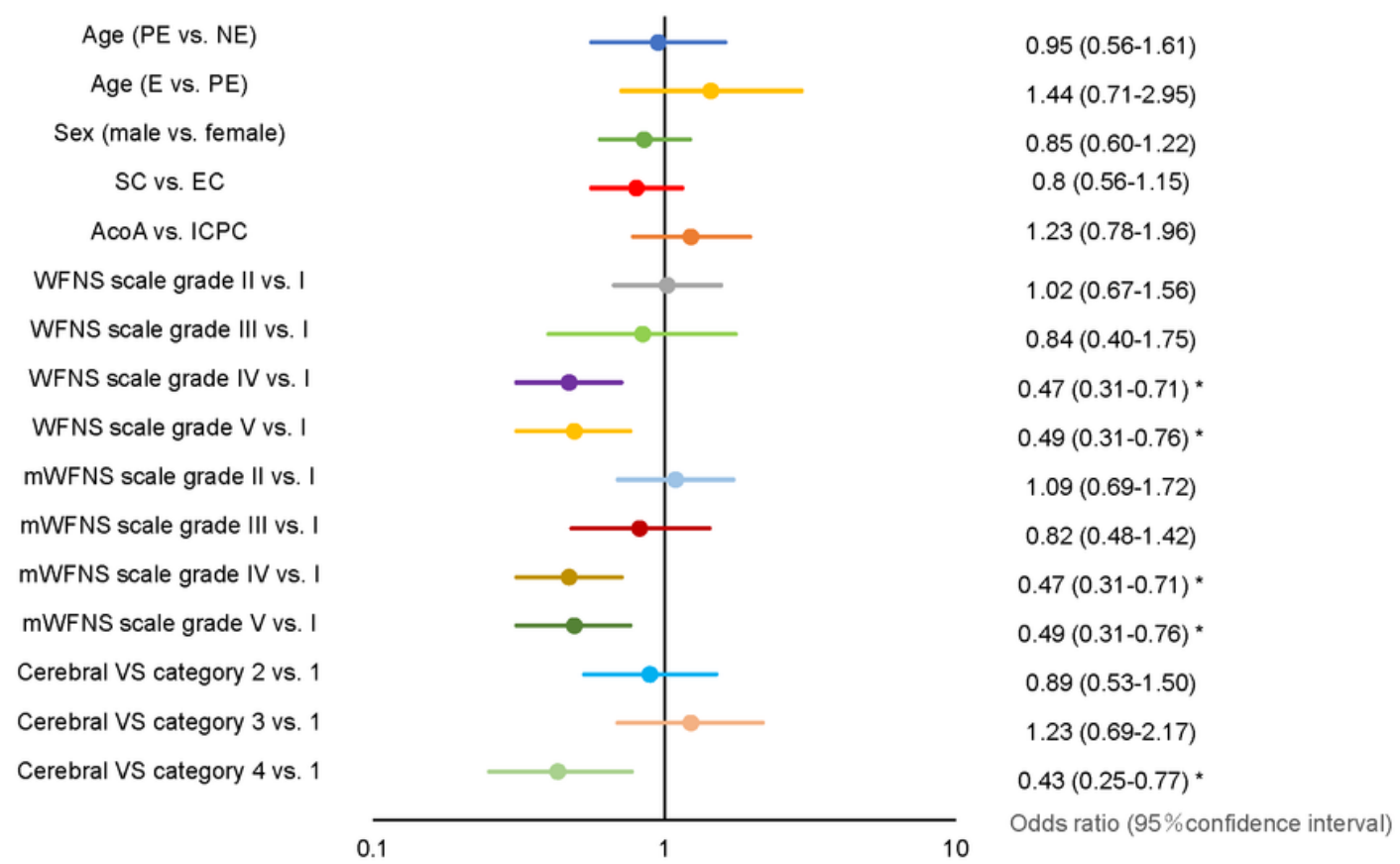

\section{Figure 2}

Forest plots for the group with improved mRS scores between discharge and at 3 months after onset. Forest plots of the factors for the improvement of mRS scores. AcoA, anterior communicating artery; EC, endovascular coiling; ICPC, internal carotid artery-posterior communicating artery; mRS, modified Rankin Scale; mWFNS, modified World Federation of Neurological Societies; SAH, subarachnoid hemorrhage; SC, surgical clipping; VS, vasospasm; NE, non-elderly; $\mathrm{PE}$, pre-elderly; E, elderly; vs., versus. *, $\mathrm{P}<0.05$.
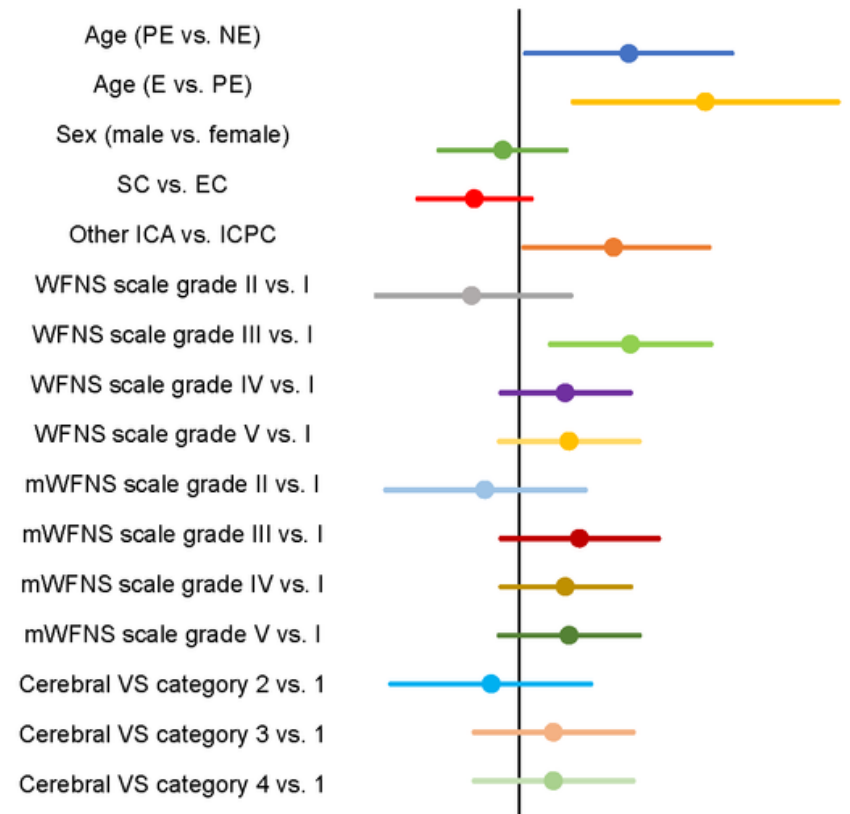

$5.7(1.1-29.2)$ *

$19.20(2.36-156.50)^{*}$

$0.77(0.28-2.09)$

$0.49(0.20-1.20)$

$4.48(1.08-20.15)^{*}$

$0.47(0.10-2.26)$

$5.86(1.64-20.87)$ *

$2.08(0.75-5.82)$

$2.21(0.73-6.68)$

$0.58(0.12-2.83)$

$2.60(0.75-9.08)$

$2.08(0.75-5.82)$

$2.21(0.73-6.68)$

$0.64(0.13-3.10)$

$0.91(0.19-4.37)$

$1.72(0.49-6.05)$

Odds ratio (95\%confidence interval) 
Figure 3

Forest plots for the group with decreased mRS scores between discharge and at 3 months after onset. Forest plots of the factors for decreased mRS scores. AcoA, anterior communicating artery; EC, endovascular coiling; ICPC, internal carotid artery-posterior communicating artery; mWFNS, modified World Federation of Neurological Societies; SAH, subarachnoid hemorrhage; SC, surgical clipping; VS, vasospasm; NE, non-elderly; PE, pre-elderly; E, elderly; vs., versus. *, $\mathrm{P}<0.05$ 